controlled ventilation with minimal oxygen is essential, tends to have inappropriate respiratory management.

Keywords: congenital cardiac disease; management; neonates; oxygen administration; transportation; ventilatory support

Prehosp Disast Med 2002;17(s2):s81-s82.

\section{Medical Service Research about Armed Forces Attending Disaster Rescue}

Senior Colonel Jiaju $\mathrm{Ni}$

Medical Service, Department of Logistics, Command Academy of Chinese People's Liberation Army

As a highly centralized and quick-responding armed group, the armed forces play an important role in disaster rescue. Most national law has authorized the armed forces to participate in disaster rescue. The armed forces are an important, constantly prepared power for disaster rescue (including medical rescue). The missions of the armed forces medical unit in disaster rescue include providing health services for the soldiers who attend to the rescue mission and to the residents of the disaster areas.

In order to fulfill the disaster rescue mission, the armed forces must be prepared in advance and be kept in a highly alert state. They should construct emergency medical service units, prepare different kinds of disaster rescue plans, and train medical personnel in the use of rescue equipment and the skills needed. In disaster rescues, the armed forces should respond quickly and arrive at the disaster site as early as possible. The command and organizing system of disaster rescue should be a combined organization of military force, police, and civilian.

Keywords: disaster; emergency medical services; medical; military, missions; rescue; response

Prehosp Disast Med 2002;17(s2):s82.

\section{M.I.E.C.O. ${ }^{\mathrm{TM}}$ (Minimally Invasive Endo Corporeal Oxygenation): Non-Pulmonary Oxygenation Method David Noble, MBBS \\ Intuitive Medical Technology}

Adequate tissue oxygenation is the most critical treatment modality in critical care medicine. Pathology (acute, subacute, and chronic) involving the conducting airways and/or lung parenchyma have a significant impact on the efficacy of pulmonary route for the delivery of oxygen to sites of oxygen uptake by the hemoglobin in the red blood cells. Current non-pulmonary methods of oxygenation include Extra Corporeal Membrane Oxygenators (ECMO) and Intravenous Oxygenators (IVOX). IVOX has limited clinical utility. ECMO is highly invasive, of limited use in prehospital settings, carries significant risks to the patient, and has limited use for long-term treatment.

The research will demonstrate that M.I.E.C.O. ${ }^{\text {TM }}$ is compatible with Pulmonary Liquid Ventilation and other modalities that may require the lung to be filled with a liquid with therapeutic properties. The research demonstrates that:

1. Minimally Invasive Endo Corporeal Oxygenation (M.I.E.C.O ${ }^{\mathrm{TM}}$ ) can achieve mixed venous saturations of $85 \%$ or greater;

2. Apparatus suitable for clinical use can be developed; and

3. Generate data to support the use of M.I.E.C.O ${ }^{\mathrm{TM}}$ in situations of cardiopulmonary dysfunction.

Keywords: cardiopulmonary dysfunction; endo-corporeal oxygenation; extracorporeal membrane oxygenation (ECMO); intravenous oxygenators (IVOX); oxygenation; oxygenators; pulmonary liquid ventilation Prehosp Disast Med 2002;17(s2)::82.

\section{Clandestine Drug Laboratories: Australia's Hidden Chemical Time Bombs}

Dr. Antony Nocera, FACEM, MSc (Emergency Planning

E' Disaster Management), ${ }^{1}$ Mr. Shaun Reynolds, B Arts, $M$ Arts (Justice Studies) ${ }^{2}$

1. Senior Lecturer in Public Health, James Cook University, and Emergency Physician, Townsville Hospital, Queensland, Australia

2. Drug Intelligence Desk Coordinator, Australian Bureau of Criminal Inteligence, Canberra, Australia

A clandestine drug laboratory is any secret or hidden place in which chemicals are used to make an illicit drug. In Australia, clandestine laboratories are almost exclusively involved in the illegal manufacture of amphetamine, methamphetamine, or their derivatives or precursor chemicals. The first Australian clandestine amphetamine laboratory was detected in Sydney in 1976. Subsequently, the number of clandestine drug laboratories in Australia has grown with the increased use of these drugs in the community. The proportion of people who had used amphetamines in the past 12 months doubled from 1995 to 1998 , while the use of heroin has remained the same. Approximately four times as many people have used amphetamines at some stage of their lives compared with heroin.

Hazardous materials incidents from clandestine laboratories can force the evacuation of hospital emergency departments and local communities. In addition to killing laboratory operators, or "cooks," these incidents can injure health and emergency service personnel. Casualties from clandestine laboratory incidents potentially present an unknown chemical hazard to emergency service and health personnel, and a difficult management problem when they are seriously injured as a result of laboratory fires, explosions, or booby traps.

Clandestine drug laboratories are a growing risk to public health. Casualties from clandestine drug laboratories may present to either general practitioners or hospital emergency departments in both urban and rural areas. The "cat's urine" smell of phenylacetic acid is characteristic of methamphetamine production.

Keywords: amphetamine; Australia; drugs; emergency departments; hazardous materials; laboratories, clandestine; methamphetamine Prebosp Disast Med 2002;17(s2):s82.

\section{Emergency Medical Services Education-Evaluating the Need for Undergraduate and Graduate Degree Programs in Wisconsin \\ Patricia Padjen, $M B A, P b D$ \\ Emergency Medical Services Program, University of Wisconsin- Madison, USA}

Objective: In the state of Wisconsin, emergency medical service (EMS) preparation involves a certification course or associate's degree. The University of Wisconsin Hospital and Clinics EMS Program investigated the need for development of a bachelor's degree in EMS management, a 
master's degree in EMS management/education/research or disaster management/medicine, and a doctorate in disaster management/medicine.

The purpose of the study was to identify whether a need exists for these proposed educational programs and what course content should be included.

Method: A questionnaire was sent to all ambulance services licensed at the paramedic level and to Wisconsinapproved paramedic training centers. Questions included current academic degrees, age, years in EMS, job title, training, degree interests, personal and organizational benefits, barriers, and existing/new skills. Data were analyzed using descriptive statistics and correlations.

Results: The questionnaire was completed by 288 respondents, a $42 \%$ return rate. One hundred seventy-three responses expressed interest in an undergraduate (bachelor's) degree with a major in EMS, 116 in a graduate (master's) degree in EMS, 82 in a master's in disaster management, and 56 in pursuing a doctorate. The principal reasons cited for pursing higher education were self-satisfaction and promotion. The major barrier was available time. Desired course content included computer-based learning, communication, and EMS management.

Conclusions: There is a need and a desire for higher-level education in EMS and disaster management. Due to limited resources, multiple universities should develop collaborative programs; and distance learning courses should be considered.

Keywords: education; emergency medical service; EMS; EMS degree programs; paramedic; Wisconsin

Prehosp Disast Med 2002;17(s2)s82-:s83.

\section{Medical Awareness and Response to Incidents at Major Hazard Facilities} Andrew Pearce, BSc (Hons), BMBS, FACEM; ${ }^{1}$ David G.E. Caldicott, BSc (Hons), MBBS (London); ${ }^{2}$ Nicholas A. Edwards, MBBS, FRACP, FFICANZCA,3 Tony Eliseo ${ }^{4}$

1. Staff Specialist, Emergency Department and Trauma Service, Royal Adelaide Hospital

2. Registrar, Emergency Department, Royal Adelaide Hospital

3. Staff Specialist, Intensive Care Unit, Royal Adelaide Hospital

4. Staff Specialist, Emergency Department, Flinders Medical Centre, Adelaide, South Australia, Australia

Introduction: Major Hazard Facility (MHF) is a term applied to a facility in which dangerous substances are stored or manufactured, and which is of a size such that an incident occurring at it may have serious consequences for the community. By definition, incidents at MHFs have the capacity to significantly impact upon health facilities. Recent mass casualty incidents around the world have forced greater emphasis on major incident and disaster planning and response. However, there still appear to be significant deficiencies in interagency communication and coordination. It was hypothesized that medical facilities in South Australia (SA) were largely unaware of MHF sites or contents, and were unprepared to deal with major incidents involving them.

Methods: There are 12 listed MHFs in SA. Directors of the Emergency Departments (ED) of all tertiary, referral medical centers in this state were interviewed using a structured questionnaire.

Results: All of the EDs were unaware of Major Hazard Facilities in their region, did not have major incident plans specific to these facilities, and appeared unprepared to deal with major incidents at these sites.

Conclusions: On the basis of this finding, in order to improve planning for such incidents, a multi-agency research collaborative, the Mass Casualty and Terrorist Incident Collaboration (MACTI) was formed. Its functions include the facilitation of inter-agency communication and dissemination of information.

Keywords: Australia; awareness; collaboration; communications; emergency department; inter-agency; event; hazard; Major Hazard Facility (MHF); planning; plans; response; risk; substances, dangerous Prehosp Disast Med 2002;17(s2):s83.

E-mail: andrew.pearce@adelaide.edu.au

\section{Hazmat Medical Life Support Program, Ministry of Health, Singapore M.K.F. Leong; R. Ponampalam; F.C.Y. Lee; S.H. Gob}

Singapore is a leading petrochemical production, storage, and trading hub in the region. There exists a potential for a technological event involving a wide variety of industrial chemicals. The 1995 Tokyo subway sarin gas attack and the recent reports of terrorist activity in Singapore served to remind us that hazardous chemicals in our midst can have devastating effects on the civilian population.

The Hazmat Medical Life Support Program, conceived in 1999, is a Ministry of Health-funded program that aims to provide education and training for medical, nursing, and paramedical staff who may be called upon to respond to and deal with a hazmat incident and casualties. The program administers four courses: (1) Basic Provider; (2) Hospital Provider, (3) Hospital Decontamination; and (4) Hazmat Medical Operations.

As hazmat incidents that result in mass casualties are relatively infrequent events, course formats and materials have been designed to provide a rational, practical, and easy-to-recall algorithm for the novice responder. Concepts, rather than systematic coverage of all available chemicals, provide a mental and practical framework for the emergency medical worker to respond to an incident, as well as to provide life support to hazmat casualties. An example of a fundamental concept is the chain of survival of a hazmat casualty: early recognition and activation of hazmat plan, administration of antidotes, decontamination, and hazmat medical life support. Issues pertaining to the triage, evaluation, and treatment of casualties in a potentially hazardous environment are covered with the teaching of a modified primary survey. The program also emphasizes standardization of instruction, assessment of competencies, and certification, and is an important tool for employers deciding on the appropriate use of their staff during a hazmat incident.

Keywords: casualties; chemical; courses; education; hazardous materials; Hazmat

Medical Life Support Course; industry; plan; primary survey; training Prebosp Disast Med 2002;17(s2):s83. 